\title{
Endoscopic submucosal dissection with a scissors-type knife for colonic lipoma
}
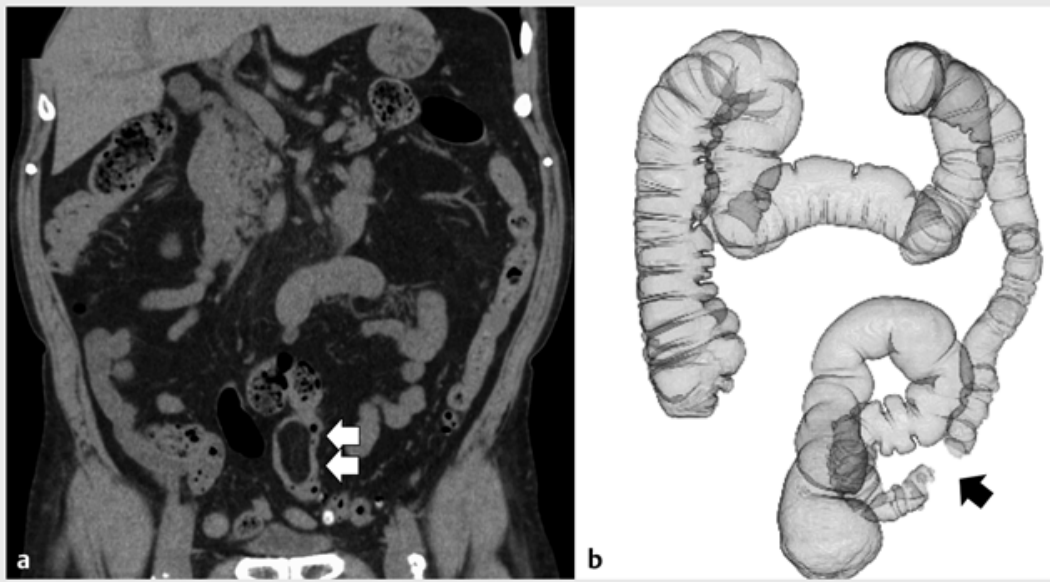

Endoscopic resection for large colonic tumors can be difficult as snaring for endoscopic mucosal resection may be challenging and the entire lesion may be difficult to visualize, increasing perforation risk [1]. On the other hand, reports of successful endoscopic submucosal dissection (ESD) for colonic submucosal tumors are increasing [2]. Scissors-type knives have an enhanced ability to grasp tissue layers selectively, rotate the knife, and achieve hemostasis [3]. We report successful use of the scissors-type knife SB Knife Jr 2 (Sumitomo Bakelite, Tokyo, Japan) in ESD of a large, pedunculated colonic lipoma.

A 75-year-old man presented with abdominal distention. Computed tomography (CT) confirmed a hypodense,

- Fig. 1 Computed tomography (CT) with contrast. a Coronal view revealing a hypodense, clearly delineated mass measuring $5 \mathrm{~cm}$ in the sigmoid colon (arrows) and no signs of large bowel obstruction. b CT colonography suggested a potentially obstructive mass (arrow), with no dilatation of the proximal colon.
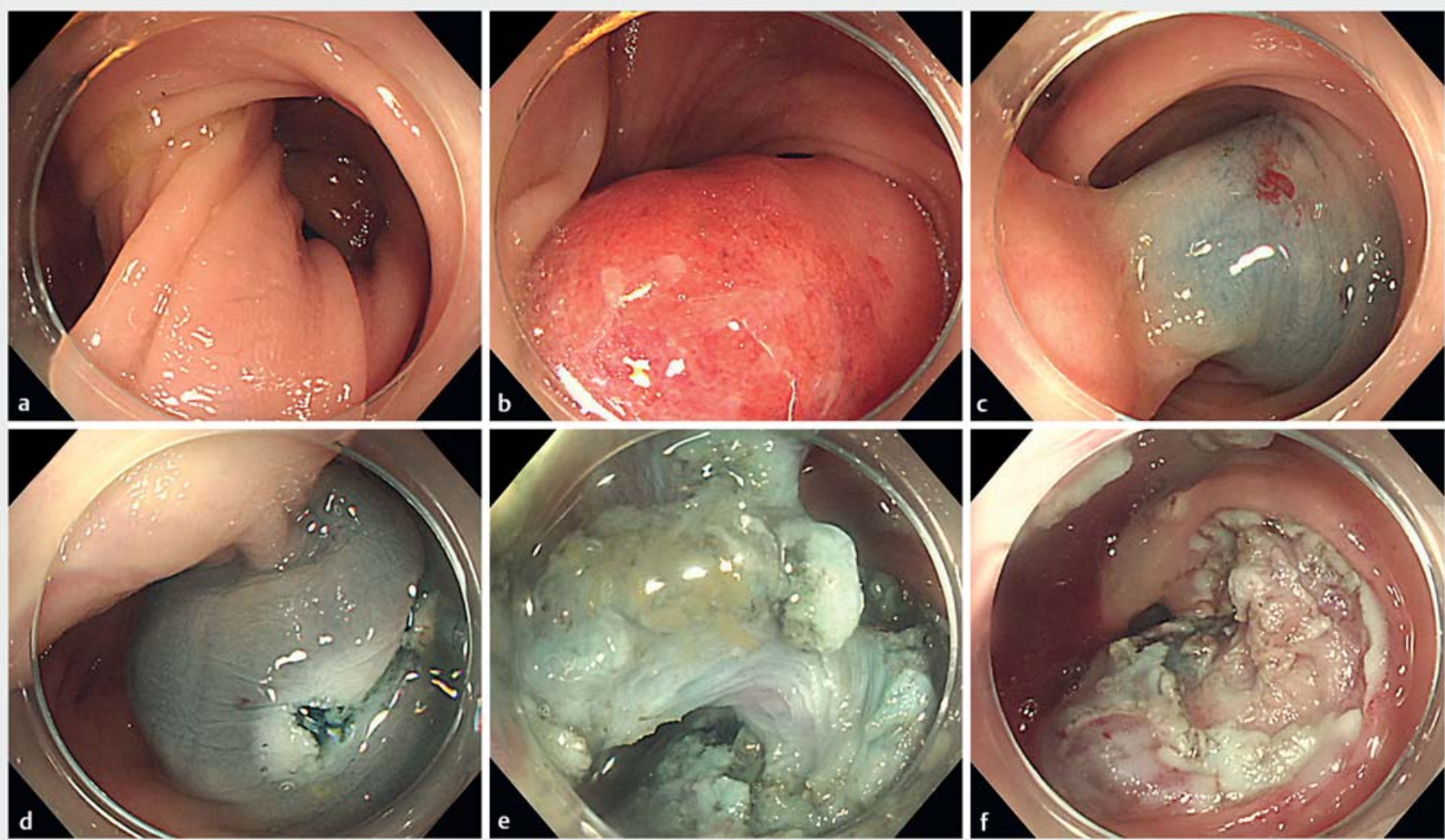

Fig. 2 Endoscopic submucosal dissection using PCF-H290I (Olympus Corp., Tokyo, Japan) with a transparent hood. a,b Stalk and head of the large pedunculated tumor. c A lifting solution containing saline, epinephrine, and indigo carmine was injected into the submucosa, clearly delineating the tail end of the tumor. $\mathbf{d}$ Circumferential mucosal incision. e Submucosal dissection. The stalk was coagulated slowly to prevent bleeding. $\mathbf{f}$ En bloc resection was achieved with no complications. 
clearly delineated mass measuring $5 \mathrm{~cm}$ in the sigmoid colon ( $>$ Fig. 1a). CT colonography suggested a potentially obstructive mass, but no proximal dilation was observed (> Fig. 1b).

A large, pedunculated lesion was ob-

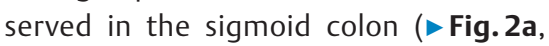
- Fig. 2b). The spastic colon and the patient's inability to stay still made it difficult to maintain scope position or endoscopic view. Because an endoloop could not be placed, ESD was performed using an SB Knife Jr 2 ( $\vee$ Video 1 ). When a lifting solution containing indigo carmine was injected into the submucosa, the color change clearly marked the end of the tumor ( Fig.2c). Circumferential mucosal incision and subsequent submucosal dissection were performed with minimal bleeding, and en bloc resection was achieved ( $\mathbf{F i g . 2 d , ~} \mathbf{F i g . 2 e}$, > Fig. 2f). Pathology confirmed complete resection of a colonic lipoma ( $>$ Fig. 3 ).

Use of scissors-type knives has been reported in ESD of pedunculated colonic polyps and small bowel lipomas [4,5]. Unlike traditional ESD knives, the scissors-type knife can cut without putting pressure on the stalk, which may cause pedunculated lesions to change position unpredictably. The knife's ability to grasp and pull allowed for clear visualization of the portion being cut and avoided deep thermal damage, even when the endoscope was perpendicular to the colonic wall. Effective hemostasis was also achieved with one device. The scissorstype knife, therefore, may be a safe option for pedunculated lesions.

\section{Competing interests}

The authors declare that they have no conflict of interest.

The authors

\section{Takeshi Okamoto $^{\circledR}$, Takashi Ikeya ${ }^{\circledR}$, Katsuyuki Fukuda}

Department of Gastroenterology, St. Luke's International Hospital, Tokyo, Japan

\section{$\triangle$ VIDEO}

\section{Endoscopic submucosal dissection with scissors-type knife for c is oma}

Takeshi Okamoto, Takashi Ikeya, and Katsuyuki Fukuda

$$
\text { St. Luke's International Hospital, Tokyo, Japan }
$$

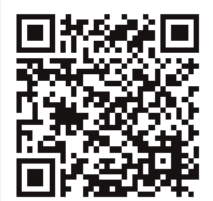

- Video 1 Endoscopic submucosal dissection of a large, pedunculated lipoma in the sigmoid colon using a scissors-type knife.
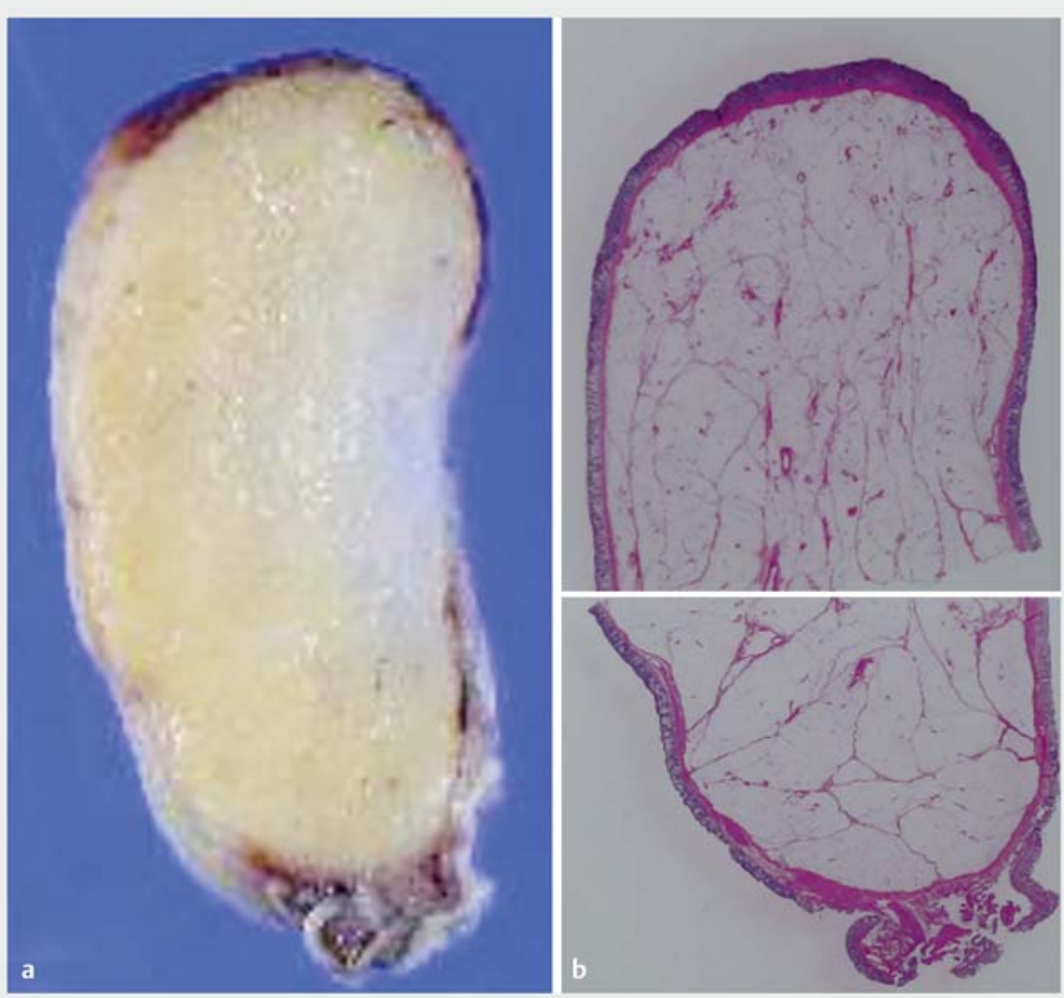

Fig. 3 Resected specimen. Complete resection was confirmed by a cross section and b hematoxylin and eosin staining without magnification. 
Takeshi Okamoto, MD

Department of Gastroenterology, St. Luke's International Hospital, 9-1 Akashicho,

Chuo-ku, Tokyo 104-8560, Japan

Fax: +81-3-3544-0649

okamotot@luke.ac.jp
[1] Yu HG, Ding YM, Tan S et al. A safe and efficient strategy for endoscopic resection of large, gastrointestinal lipoma. Surg Endosc 2007; 21: 265-269

[2] Okada K, Shatari T, Suzuki K et al. Is endoscopic submucosal dissection really contraindicated for a large submucosal lipoma of the colon? Endoscopy 2008; 40: (Suppl. 02): E227

[3] Shiratori Y, Ikeya T, Fukuda K. Introducing the newly developed SB Knife Jr 2: enhancing creative endoscopic submucosal dissection. Endoscopy 2020: doi:10.1055/a-12924426

[4] Jawaid S, Draganov PV, Yang D. Endoscopic resection of large pedunculated colon polyps using only a scissor-type knife: a case series. VideoGIE 2020; 5: 264-266

[5] Toya Y, Endo M, Orikasa S et al. Lipoma of the small intestine treated with endoscopic resection. Clin J Gastroenterol 2014; 7: 502505

\section{Bibliography}

Endosc Int Open 2021; 09: E1023-E1025

DOI 10.1055/a-1485-1262

ISSN 2364-3722

(C) 2021. The Author(s).

This is an open access article published by Thieme under the terms of the Creative Commons Attribution-NonDerivativeNonCommercial License, permitting copying and reproduction so long as the original work is given appropriate credit. Contents may not be used for commercial purposes, or adapted, remixed, transformed or built upon. (https:// creativecommons.org/licenses/by-nc-nd/4.0/)

Georg Thieme Verlag KG, Rüdigerstraße 14, 70469 Stuttgart, Germany

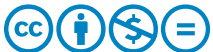

